\title{
PRELIMINARY NOTE ON AN AUTOMIATIC RECORDER GIVING A CONTINUOUS HEIGHT RECORD OF THE KENNELLY-HEAVISIDE LAYER
}

\author{
By T. R. Gilliland and G. W. Kenrick
}

\section{ABSTRACT}

This paper describes a preliminary installation of a continuous automatic recorder of virtual heights of the Kennelly-Heaviside layer. This installation requires that a chopper at the transmitter and a revolving mirror at the receiving station be driven by synchronous motors connected to the same power system. The group retardation method of Breit and Tuve is used with a few modifications which permit continuous records to be made. Suggestions are made for improvements which might be incorporated in a permanent installation.

I. Introduction

II. Principle of operation of the recorder

III. Construction details............ 786

IV. Suggestions for improvement.

V. Conclusion

\section{INTRODUCTION}

During the last few years measurements of the virtual height of the Kennelly-Heaviside layer have commanded no little interest and numerous papers have been published describing such observations. In America most of the workers have employed the group retardation or pulse method originated by Breit and Tuve inmaking the measurements reported. ${ }^{23}$

The principle employed in this method may be understood by reference to Figures 1 and 2.

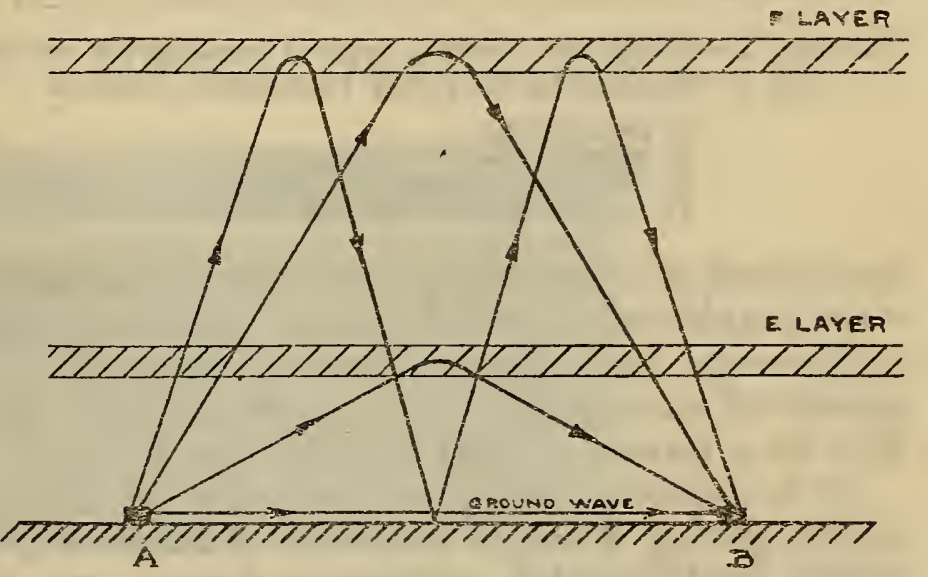

FIGURE 1.-Diagram showing various paths by which pulse may arrive at receiving station

A very short pulse or dot is transmitted from point $A$ and may arrive at point $B$ by several paths as indicated in Figure 1 . The pulses arriving at the receiver over the ground and along the several paths

1 Sэe Breit and Tuve, Physical Rev., vol. 21, pp. 554-576, 1926; Proc. I. P. E., vol. 16, pp. 1236-1239. Eeising, R. A., Proc. I. R. E., vol. 16, pp. 75-99. de Mars, Gilliland, and Kendrick, Froc. I. R. E., vol. 19, pp. 106-113.

2 For other methods see Appleton, E. V., Proc. Royal Soc., vol. 109, p. 621, 1925; vol. 113, p. 450, 1926; vol. 115 , p. 291,1927 ; vol. 117, p. $576 ; 1928$.

8 For other American methods see Mirick \& Hentschell, Proc. I. R. E., vol. 17, pp. 1034-1041. 
result in several pulses at the receiver for each transmitted pulse. If the output of the receiving set is led to an oscillograph, a record similar to that shown in Figure 2 may be obtained. Figure $3 \mathrm{a}$ is an actual oscillogram obtained by this method showing pulses which have arrived by several paths, while Figure $3 \mathrm{~b}$ shows the ground pulse and only one reflection. If the oscillograph film speed is known, the time interval between the arrival of the ground pulse and any of the reflected pulses may be measured, and from this the virtual height of the layer may be computed.

The major difficulty with the method described above, and one which is common to most methods so far reported, is that each oscillogram taken gives the virtual height only over a brief period, usually a fraction of a second. In order to obtain a clear idea of the variation of the layer height over a considerable period, such as 24 hours for instance, it is necessary for the observer to remain at the apparatus and take frequent oscillograms, each of which gives him but a single point on his desired curve of virtual height as a function of time. Such observations hence require considerable resources in personnel and supplies (notably film) when more than a few frag-

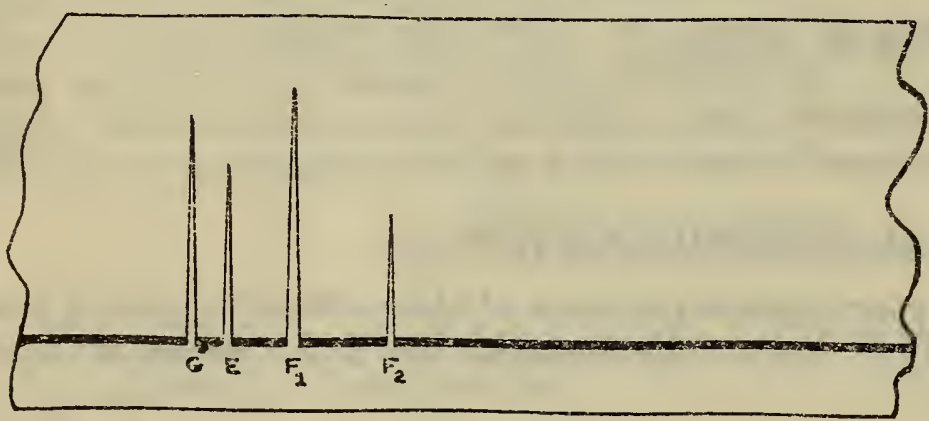

FIGURE 2.-Diagram showing type of oscillogram which may be obtained by the group retardation method

\section{$G$, ground pulse.}

E, reflection from low (E) layer.

$F_{1}$, first reflection from high $(F)$ layer.

$F_{2}$, second reflection from high $(F)$ layer. mentary measurements are to be made. In fact, several hundred feet of film are usually required for a 24-hour run, and as the labor of subsequent development and measurement of the oscillograms taken is considerable it is probable that the entire time of no less than six workers would be necessary to secure a continuous record of layer height over any considerable period if such methods were employed. In order that the different pulses may be separated sufficiently for accurate measurement, it is necessary to use film speeds of the order of 10 feet per second. This means that sensitive film or a powerful light source must be used.

It is evident, therefore, that the development of some automatic device giving a height record is of major importance to any program which contemplates continuous measurements of layer height. This paper describes a preliminary set-up which has proven the practicability of a scheme for making continuous height records, and improvements are suggested which might be incorporated in a permanent installation.

\section{PRINCIPLE OF OPERATION OF THE RECORDER}

With a few modifications, the group retardation method as described above may be used to give continuous automatic records. The general scheme may be best understood by reference to Figure 4 . The pulses are sent out from a transmitter which is keyed by a chopper 
B. S. Journal of Research, RP373

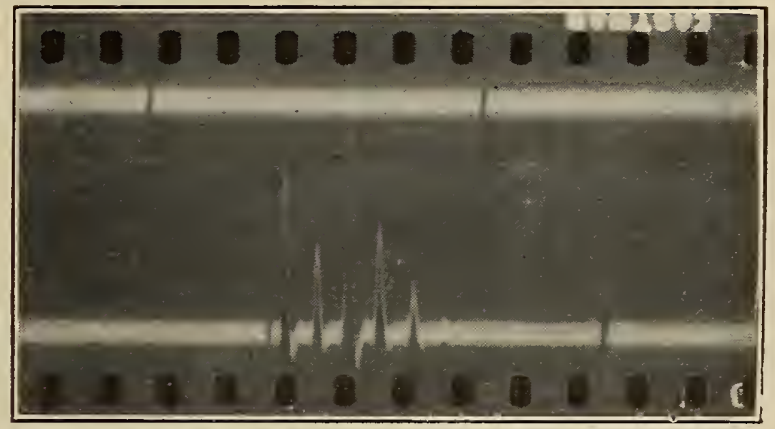

Figure 3a.-Actual oscillogram obtained by group retardation method showing impulses which have arrived by several paths

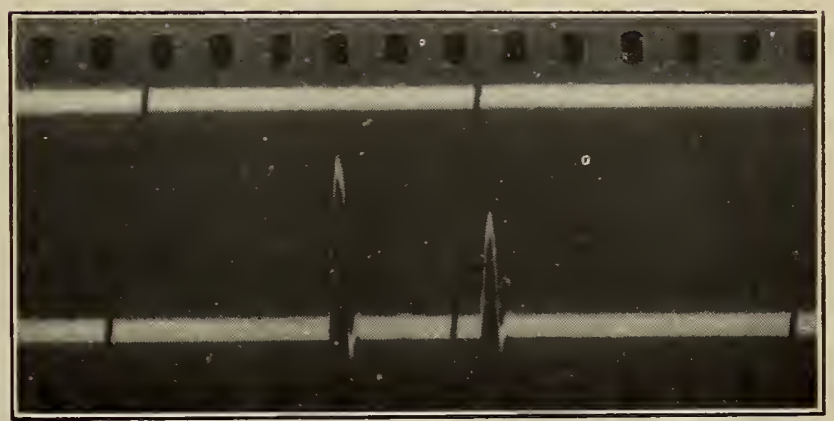

FIGURE 3b.-Oscillogram showing ground pulse and one reflection 


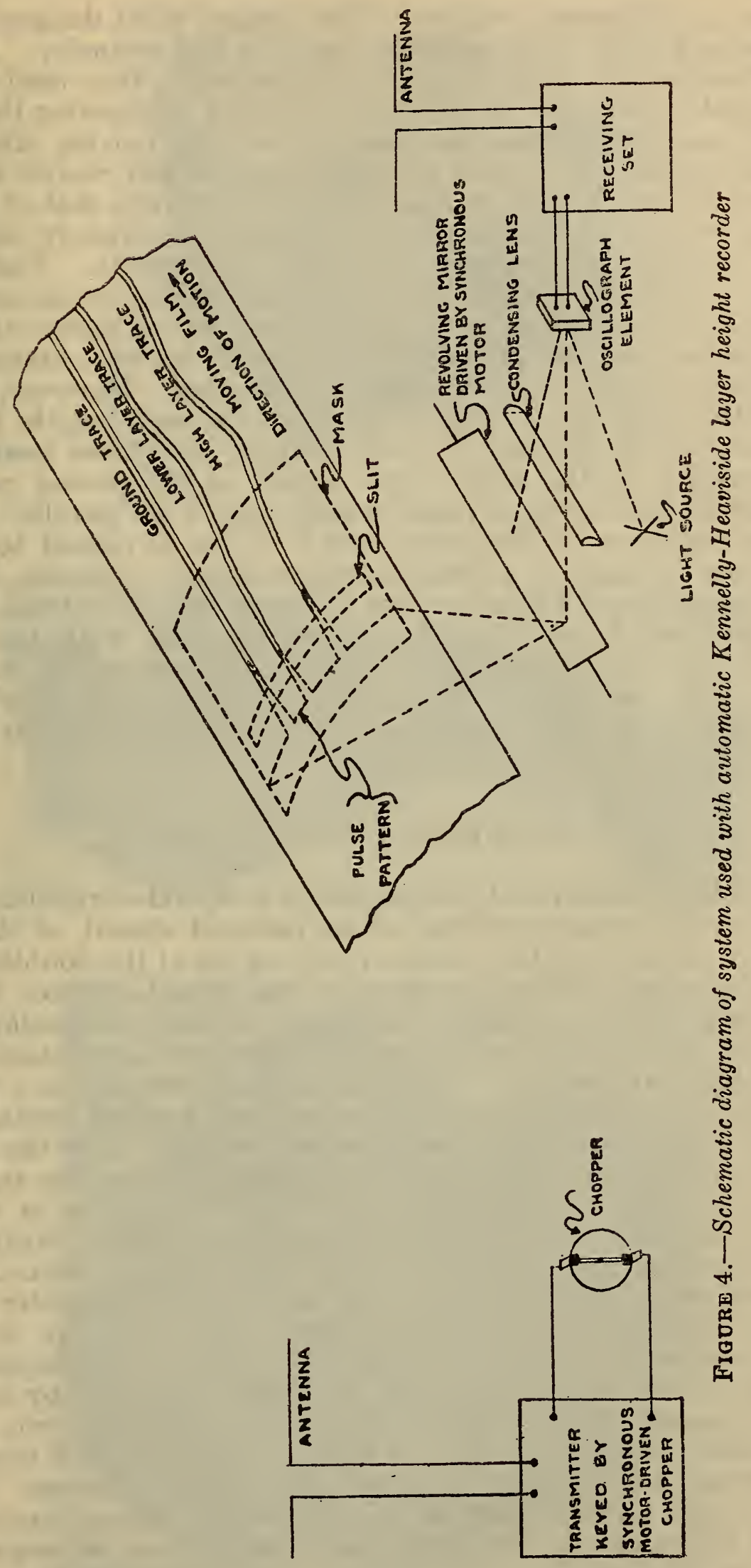


driven by a synchronous motor. The chopper is so designed that the pulses will be of short duration (say, $2 \times 10^{-4}$ seconds). At the receiving station the apparatus is very similar to that used in the original method with the exception that instead of directing the light from the oscillograph element directly on the moving film, the automatic recorder employs a rotating mirror which rotates in synchronism with the chopper so that a pattern similar to that of Figure 2 may be viewed on a screen in the manner commonly used for viewing recurring phenomena with the oscillograph. "The peak marked $G$ in Figure 2 should remain fixed in position on the screen if the chopper motor and the motor driving the rotating mirror are kept in synchronism, because the length of the path between transmitter and receiver for this impulse remains unchanged. However, if the Kennelly-Heaviside layer changes in height, the path lengths for the other impulses $\left(\mathrm{E}, \mathrm{F}_{1}\right.$ and $\mathrm{F}_{2}$ ) will change, and these peaks will shift in position on the screen with respect to the ground peak $G$. If, in place of the screen, a mask is used with a slit parallel to and above the base line of the peaks, and if a film is caused to move slowly across the mask in a direction perpendicular to the slit, a trace will be recorded on the film for each of the peaks. The trace representing the ground pulse should be a straight line, while the other traces will vary in distance from the ground trace as the layer or layers move up and down. The distance from any of these traces to the ground trace will be a measure of the virtual height corresponding to that particular reflection.

\section{CONSTRUCTION DETAILS}

The installation described here employed a crystal-controlled transmitter with the chopper connected in the grid circuit of the first amplifier. At the recording point a receiving set of the double-detection type was used, with the output of the second detector feeding into one stage of d. c. amplification which operated the oscillograph. The system was similar to that used in previous installations with the exception that the receiving set was operated from the a. c. mains.

In carrying on observations by the original method trouble was frequently encountered from interference coming in over the power lines. It was noted that these disturbances were quite often at power frequency, so that disturbance patterns could be made to remain stationary on the oscillograph screen when the rotating mirror was driven directly by a synchronous motor. Obviously spurious results would be obtained from this source by an automatic recorder which employed a chopper and rotating mirror driven directly by synchronous motors. In order to obviate this difficulty, the chopper and rotating mirror were geared to the synchronous motors by an odd gear ratio, namely, 127 to 64 , so that any disturbance patterns occurring at power frequency would not remain stationary and thus give spurious traces on the film, but would drift gradually across. However, the pulse patterns due to the transmitter remain stationary except for the relatively slow drift due to change in layer height, and the light on the film from these patterns is predominant over that from sources of disturbance. 
B. S. Journal of Research, RP373

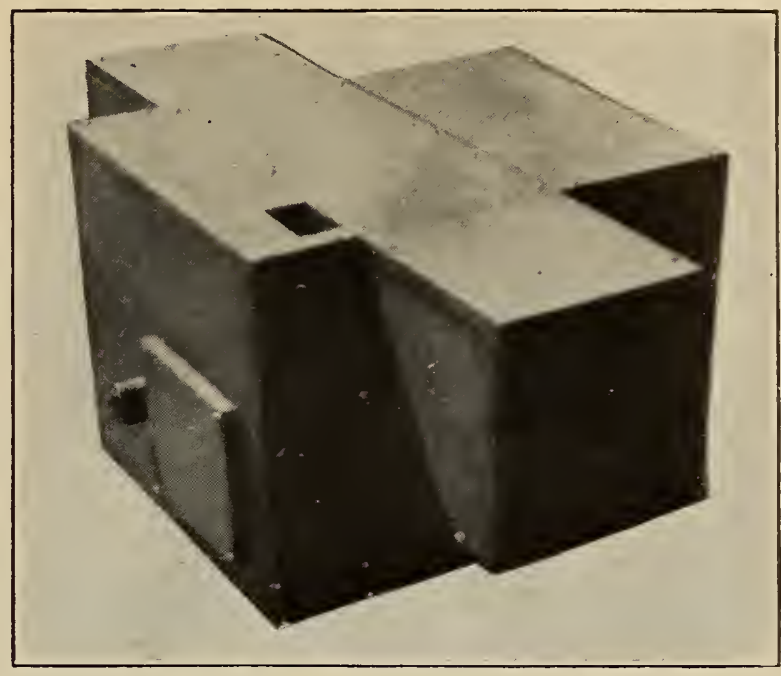

Figure 6.-Photograph of complete recorder with film container in place

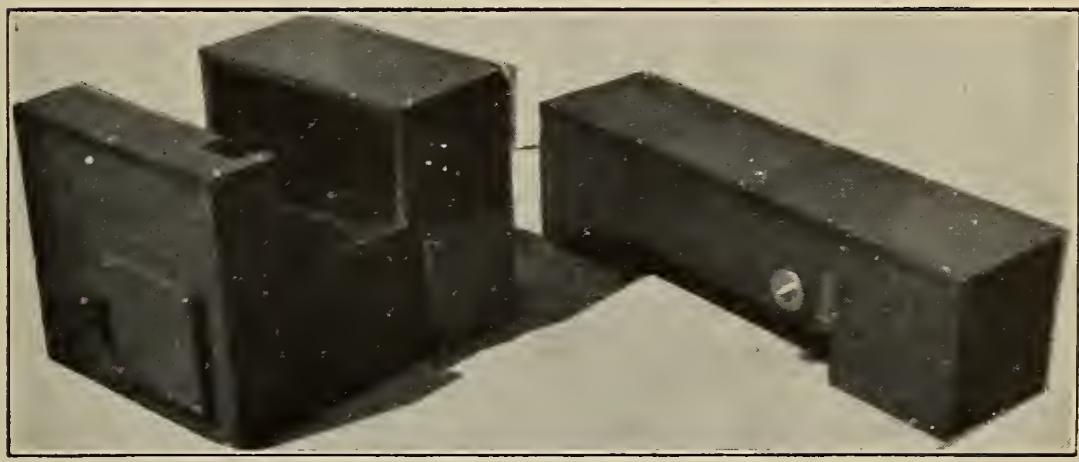

FiguRE 7.-Recorder with film container removed

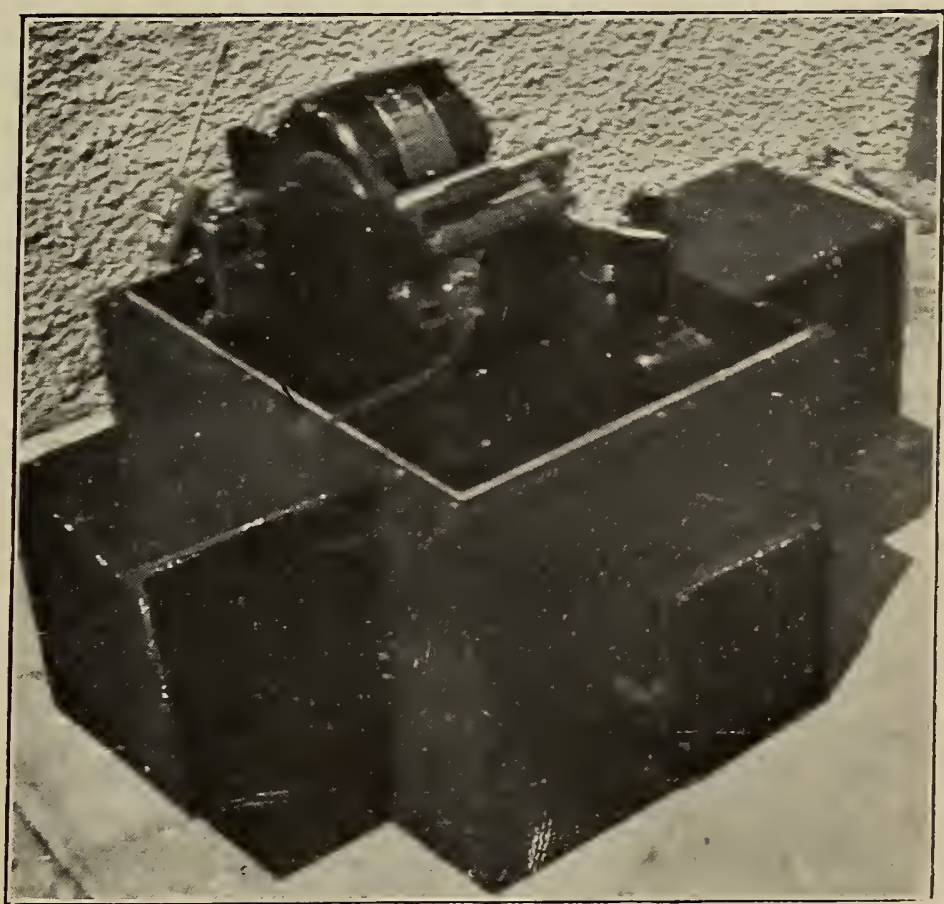

FIGURE 8.-Photograph of synchronous motor, rotating mirror, oscillograph element, and lamp

The gears for driving the film are shown at the left 
B. S. Journal of Research, RP373

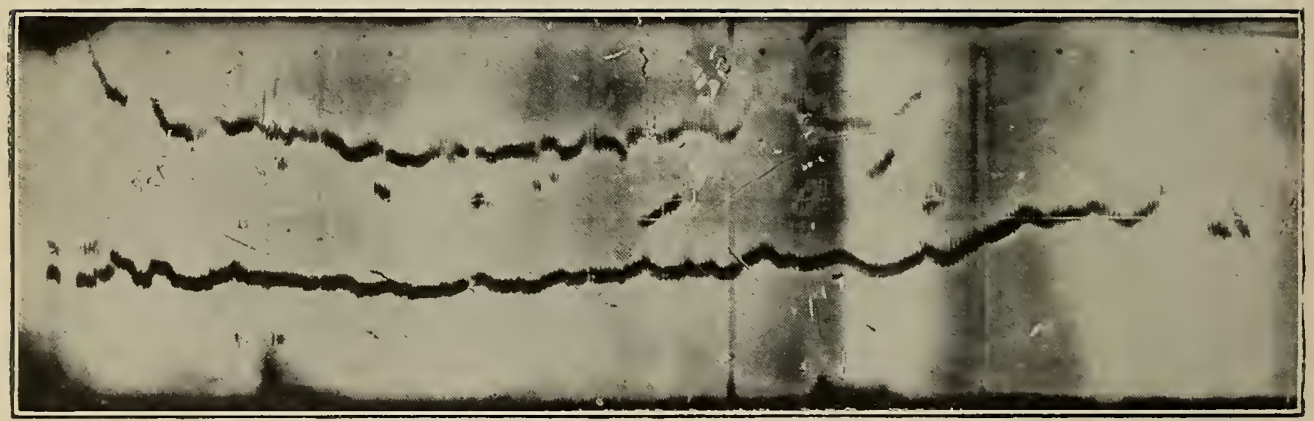

FIGURE 9.-Example of height record showing gradual rise of layer from 241 $\mathrm{km}$ to $399 \mathrm{~km}$

Note also temporary appearance of other layers. Record runs from $5.30 \mathrm{p}$. m. to $2.15 \mathrm{a} . \mathrm{m}$., June 13, 1931. Frequency 4,045 kc. Ground trace appears at botton of record. 
The film was driven through a system of gears by the same synchronous motor used for driving the rotating mirror. A film speed of 2.5 feet per 24 hours was used. A six-volt automobile lamp bulb was employed as a light source for the oscillograph. Figure 5 is a drawing of the assembly with film drive and film container omitted. Figure 6 is a photograph of the complete recorder with film container in place. Figure 7 shows the film container removed while Figure 8
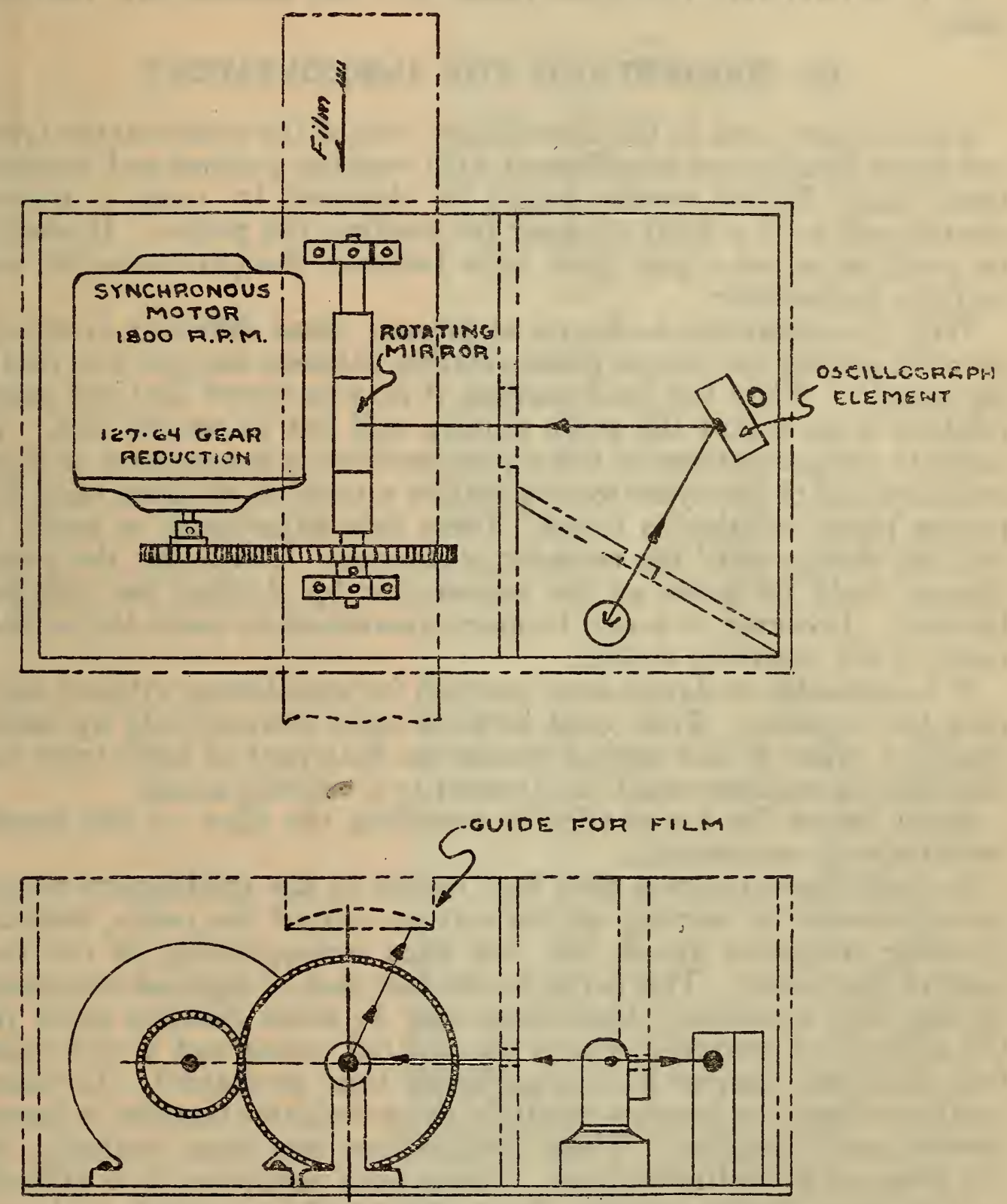

FIGURE 5.-Drawing of assembly of recorder with film drive and film container omitted

is a photograph of the synchronous motor, rotating mirror, oscillograph element, and lamp. The gears for driving the film are shown at the left.

Figure 9 is a typical record which shows the variation in height over a period of $8 \frac{3}{4}$ hours. The frequency was $4045 \mathrm{kc}$ and the distance from transmitter to receiver was 3 miles. 
The advantages of this system may be enumerated as follows:

1. It gives a continuous automatic record.

2. It requires only a small fraction of the amount of film used by other methods. A less sensitive film and weaker light source may be used.

3 . It requires little attention.

4. It will record heights of two or more layers simultaneously.

5 . It is relatively free from power line and atmospheric disturbances.

\section{SUGGESTIONS FOR IMPROVEMENT}

The chopper used in this installation was of the commutator type, and some trouble was experienced with wearing brushes and commutator disk. Better results might be obtained by using a photoelectric cell with a light chopper for making the pulses. It should be possible to use a grid glow tube between the photo-electric cell and the transmitter.

With the apparatus as set up at present, some difficulty is experienced in getting the proper phase relation between chopper and rotating mirror. When the set is started, it may be found that the phase relation is such that the pulse pattern will not be on the film. In order to get the pattern in the proper position it is necessary to start and stop one of the synchronous motors a number of times until the proper phase relation is found. Once this adjustment is made, it will not change until the recorder is stopped. Obviously, the phase change could be made at the transmitter by shifting the chopper brushes. However, it would be more convenient to make the adjustment at the receiving station.

It is advisable to devise some method for monitoring without stopping the recorder. This could be done most conveniently by introducing a prism in the optical system so that part of light from the oscillograph element could be diverted to a viewing screen.

Some device for automatically recording the time on the record would also be convenient.

Investigations indicate that best results in the preliminary set-up are attainable by working at the extreme top of the peaks, thereby avoiding confusion due to the two lines corresponding to the two sides of the pulses. This is due to the fact that at high mirror speeds (giving high resolution) these lines may be some distance apart (in the absence of extremely sharp transmitted pulses and a very carefully designed receiver having negligible time constants). Developments are hence in progress to attain these desirable features in transmission and reception. These double lines are most confusing in the presence of multiple layers. Under such conditions it is difficult to recognize whether specific lines correspond to upward or downward motions of the light beam from the base line of the peaks. The tops of the peaks are readily maintained at a fixed height by arranging the resistance-coupled amplifier circuit so that the incoming signal reduces rather than increases the current through the element. It is readily possible with a high gain set such as employed in the experiments described, to reduce this current to practically zero when the incoming pulse has a moderate amplitude. This results in a fixed position of the top of the pulses which corresponds to the zero 
current position of the light beam. This position has the advantage of being practically unaffected by changes in the operating plate current of the last amplifier tube due to voltage fluctuations, etc.

\section{CONCLUSION}

Aside from developments for improving the reliabilty of the recording system so as to insure the continuity of records, it appears probable that problems arising in the interpretation of these records are likely to be of paramount importance. Thus, the complex records obtained in the presence of "split peaks," multiple refiections, and other intricate phenomena, greatly complicate the work of interpretation of the records. Reinforced and interpreted by supplementary records taken by the oscillographic methods previously employed, however, continuous records of this kind represent a distinct addition to the methods heretofore available for the study of Kennelly-Heaviside layer phenomena.

Washington, August 21, 1931. 